1 Diabetes Research Centre University of Leicester, Leicester, UK

2 Division of Psychiatry and Applied Psychology, School of Medicine University of Nottingham, Nottingham, UK

3 Department of Primary Care and Public Health, Imperial College London, London, UK

4 British Medical Association, General Practitioner partner, London, UK

5 Department of Primary Care and Public Health, Imperial College London, London, UK

6 Workforce Race Equality Implementation Team, NHS England UK

Correspondence to K Khunti kk22@leicester.ac.uk Cite this as: BMJ2021;372:n602 http://dx.doi.org/10.1136/bmj.n602 Published: 15 March 2021

PRACTICE POINTER

\title{
Assessing risk for healthcare workers during the covid-19 pandemic
}

\author{
Kamlesh Khunti, ${ }^{1}$ Amanda Griffiths, ${ }^{2}$ Azeem Majeed, ${ }^{3}$ Chaand Nagpaul, ${ }^{4}$ Mala Rao $0^{5,6}$
}

\section{What you need to know}

- In addition to risk factors for severe covid-19 identified across broader populations, such as older age and male sex, data from the UK and the US have shown that healthcare staff of ethnic minority backgrounds have been disproportionately affected by covid-19

- Risk assessment of the workplace, workforce, and individual can help reduce potential workplace hazards for all staff, regardless of ethnicity

- Individuals who are at greatest risk of adverse outcomes from infection may need adjustments to their roles

Severe acute respiratory syndrome coronavirus 2 (SARS-CoV-2) is a new strain of coronavirus that causes coronavirus disease 2019 (covid-19). In March 2020, the World Health Organization classified covid-19 as an international pandemic. Initial guidance from many organisations identified people who might be more vulnerable to covid-19, based on knowledge of those known to be most susceptible to adverse outcomes from the influenza virus. Health conditions divided individuals into those who are "extremely vulnerable," for whom shielding is required, and those at "increased risk of severe illness."

Studies of hospital admissions and mortality have subsequently enabled identification of more specific risk factors. They include age, sex, and underlying health conditions, the most important of which are diabetes, hypertensive disease, cardiovascular disease, and obesity. ${ }^{1}$ Concerns have also been raised in the UK and the US about ethnicity as a risk factor, because of the disproportionately higher rates of covid-19 infection and deaths in ethnic minority populations compared with white populations. ${ }^{2}$ In the UK's NHS, $21 \%$ of staff are from ethnic minority backgrounds, but non-white ethnicities accounted for $75.8 \%$ of deaths. ${ }^{3}$ In the US, Black people account for more than $20 \%$ of covid- 19 cases among health professionals despite only $5 \%$ of doctors and $10 \%$ of nurses in the US being from this group. ${ }^{45}$ The extent to which covid-19 mortality is linked to workplace exposure, cultural or social factors, ethnicity, housing, and comorbidities is not fully understood. ${ }^{2}$ However, as increasing data have emerged about risk factors for severe covid-19 during the pandemic, employers are carrying out risk assessment and management as part of their responsibility to protect employees from harm.

\section{Why is occupational risk assessment necessary?}

In the UK, employers have a responsibility created by the Health and Safety at Work Act, 1974, to protect the health and safety of their workforce, as far as reasonably practicable. ${ }^{6}$

Tackling risks under the remit of UK health and safety law involves a preventive, risk assessment approach. This includes an equitable and inclusive approach to risk management and risk reduction of potential workplace hazards for all staff regardless of ethnicity and diversity. It involves identification of what could cause injury or illness (hazard), deciding how likely it is that someone could be harmed, and how seriously (risk). Action needs to be taken to eliminate the hazard, or if this is not possible, to control the risk. The Health and Safety Executive also recommends a risk assessment framework, for example, to employers to reduce the risk of work related stress.

During the pandemic, there have been calls for the protection of all healthcare workers in primary, secondary, or community care, ${ }^{8}$ and various frameworks and tools for risk stratification have been developed in the UK and internationally..$^{-13}$ The European Agency for Safety and Health at Work has issued guidance for organisations to implement measures in place to prevent covid-19 infections, including risk assessment tools, ${ }^{14}$ and the World Health Organization has issued guidance on understanding and managing risk. ${ }^{15}$ These tools are based on best practice in occupational health and expert opinion; their effectiveness has not yet been evaluated. In this article, we present a simple framework: principles for assessing and managing covid-19 risk in healthcare settings. We describe a pragmatic approach that may be incorporated into existing risk procedures and be used as an aid to decision making. Several frameworks are currently in use in various NHS contexts, and they can be adapted to suit other healthcare settings. ${ }^{7-14}$

\section{How do you conduct a risk assessment?}

Clinicians are familiar with the concept of Clinical Risk Assessment that seeks to improve the quality and safety of healthcare. ${ }^{15}$ Most clinicians are less familiar with the concept of workplace risk assessment. The framework presented here suggests three aspects to a risk assessment that are necessary for effective decision making (fig 1). It is important to consider all three: workplace, workforce, and individual. Several published frameworks give detailed practical methods of implementing these in practice, ${ }^{79^{-14}}$ and are aimed at employers and individual line managers. 


Employers have a duty
of care requiring them,
as far as reasonably
practical, to secure the
health, safety, and wellfare
of their employees.
Managing and reducing the
risk of potential workplace
hazards for all staff involves
assessment of the
workplace, the workforce,
and the individual

Employers have a duty of care requiring them, as far as reasonably practical, to secure the health, safety, and wellfare of their employees. risk of potential workplace hazards for all staff involves assessment of the and the individual

\section{Workplace assessment}

Take into consideration healthcare setting

ie, primary, community, or hospital setting

Review of aerosol generating procedures

Potential exposure to SARS-CoV-2 in the workplace

Application of an appropriate hierarchy of control

measures including:

- Elimination if possible

- Reduction by hygiene measures

- Safe systems of work

- Election and correct use of personal protective equipment including training and fit testing

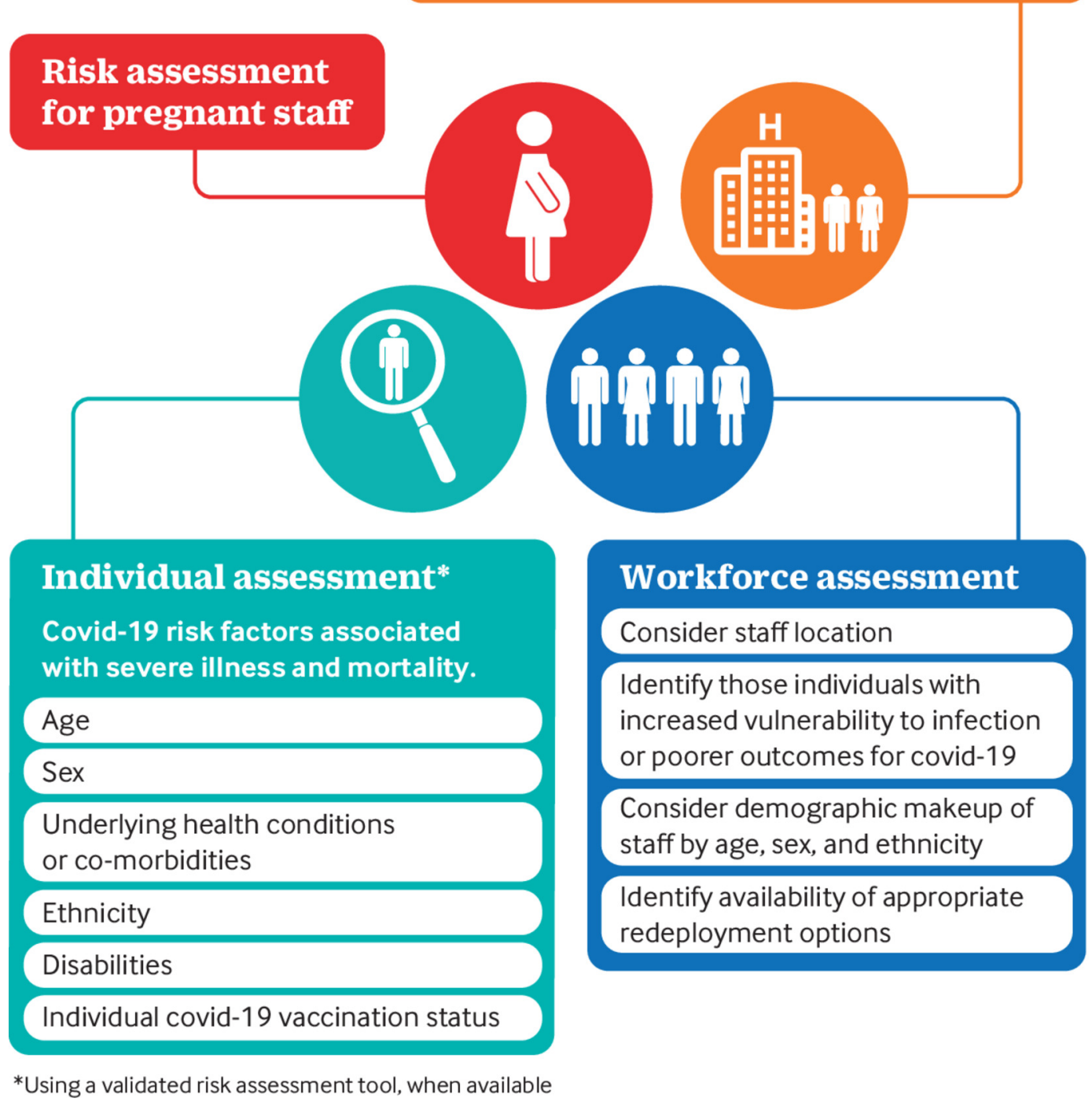

Fig 1 | Framework for risk assessment

First, an assessment of workplace factors should include measurement of exposure to help identify who may encounter the hazard in their work environment. Factors include environmental hygiene, increased environmental cleaning, social distancing, and hierarchy of other control measures, including eliminating risks if possible. With covid-19, we can identify the hazard, and to some extent the exposure (by environmental survey and testing) involved in the type of work being undertaken. 
Second, an assessment of the workforce will help employers identify, in their team or service, to what extent those staff are at risk of exposure. Employers need to consider the availability of options to redeploy staff. Key considerations include staff location (primary or community care, or hospital setting) and an exploration of activities and risks in their typical working environments-for example, whether staff work in an environment where aerosol generating procedures are performed. Managers should seek to identify in their team or service the proportion of staff who may have increased vulnerability, including data on age and ethnicity.

Third, an individual risk assessment is required for every employee to identify those with increased vulnerability to infection and adverse outcomes from covid-19. These one-to-one conversations may be conducted by a line manager, supervisor, senior manager, or health and safety representative. They should take into account age, sex, chronic health conditions, ethnicity, and pregnancy, and vaccination status of the individual. ${ }^{791617}$ Details of criteria recommended in this framework are presented in figure 1 and will be updated and refined in the light of new evidence. Several risk assessment tools have been developed based on these criteria and are in operation within the NHS..$^{-11} 13$ These are suitable for use by non-clinicians (fig 2). However, most risk tools are based on consensus and have not been validated. Exceptions include the QCOVID risk score in the UK, which uses individual level data from primary care. Although developed for assessment of population level risk, the tool can be used for healthcare workers. ${ }^{18}$

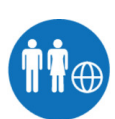

\section{Age and ethnicity}

People of Black, Asian, and minority ethnicities aged above 55 , particularly in those with co-morbidities

People of white European ethnicity aged over 60
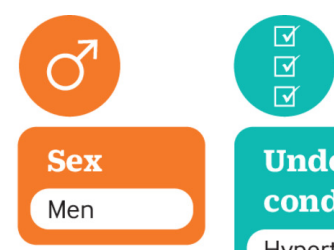

\begin{tabular}{l} 
Underlying health \\
conditions including: \\
Hypertension \\
Cardiovascular disease \\
Diabetes Mellitus \\
\hline Chronic kidney disease \\
\hline Chronic obstructive pulmonary disease \\
\hline Obesity
\end{tabular}

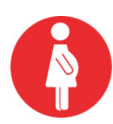

\section{Pregnancy}

All pregnant women should have risk assessment

Women $>28$ weeks pregnant or who have underlying conditions should be recommended to stay at home

Women $<28$ weeks pregnant should only work in patient facing roles where risk assessment supports this

Fig 2 | Risk assessment for the individual

Assessments should consider psychological and social factors, risk behaviours, and mental wellbeing. Individuals' understanding of risk will vary, as will their willingness to engage in a work activity that they perceive to be hazardous. Managers may not be aware of underlying health conditions in their staff, as in normal circumstances it is not appropriate to seek such information beyond functional capabilities. However, in the current situation, health assessment of all staff by a specialist (eg, occupational health) service may not be practical and inquiry by managers about the presence of health conditions is reasonable, subject to cautions about confidentiality. Such conversations between managers and staff need to be handled sensitively and supportively, to create an environment in which individuals can openly discuss their concerns. Staff may be more anxious, depressed, or traumatised than under normal working conditions. An open and positive workplace culture supports health workers to share their concerns about risk with employers and consider their preferences. Some staff may require additional advice and support.

\section{How will this help reduce the risk?}

Risk assessment should be followed by risk management: the application of a hierarchy of control measures. A holistic system of risk assessment aims to help employers make adjustments to mitigate the risk of covid-19 to staff. This starts with elimination of exposure to the hazard if possible, engineering controls of exposure to the hazard, hygiene measures, and safe systems of work, and by the selection and correct use of personal protective equipment (PPE), including training and fit testing. In doing so, it may be possible to minimise potentially high risks of infection. Individuals who are at greatest risk of adverse outcomes from infection may need adjustments to their roles, and some may require redeployment across the health system to environments that pose a lower risk.
Several practical examples of how to conduct a risk assessment of the workplace, workforce, and the individual have been published, and are relevant to all workplaces, including healthcare settings. ${ }^{1419}$

\section{Where do we go from here?}

Research and audit programmes are under way to determine the impact of covid-19 on healthcare workers, with several longitudinal studies ongoing. ${ }^{20} 21$ As more scientific evidence on covid-19 becomes available, more accurate validated risk prediction scores will facilitate more precise estimates of individual risk.

Figures to date do not suggest that doctors or nurses, particularly in intensive care units, have a higher mortality rate than the general working population. ${ }^{22}$ This may reflect a controlled working environment where exposure to the hazard can be minimised by safe systems of work and provision and correct use of PPE. Nonetheless, because of the disproportionate number of overall deaths in ethnic minority healthcare workers, risk assessments should be implemented for all healthcare workers.

Finally, risk management should involve training, measuring how well control measures are working, and learning from that experience. A risk management process should also involve consultation with staff. The pandemic has created an opportunity to improve safety in the workplace beyond covid-19, to consider cultural factors, and to ensure that all staff feel included and supported to raise concerns. How such processes have been conducted should also be evaluated to help improve risk management in the current pandemic and in any similar events in future. 


\section{Education into practice}

- What is the most effective way to ensure that all staff know they need an individual risk assessment?

- How might you approach a member of staff for a discussion about their risk profile?

- Who will know how managers, and other people responsible for carrying out these assessments, find these discussions in practice? Do they require additional information and support?

\section{How patients were involved in the creation of this article}

Patients were not directly involved with creation of this article but the authors included clinicians and managers who are involved in day-to-day decision making on occupational health and risk assessments of healthcare staff.

\section{Further information}

- Health and Safety Executive. What to include in your COVID-19 risk assessment. https://www.hse.gov.uk/coronavirus/assets/docs/riskassessment.pdf

- Supporting Occupational Health and Wellbeing Professionals. Occupational Health Risk Assessment Guidance.

https://www.som.org.uk/occupational-health-risk-assessmentguidance

Acknowledgments: We would like to thank Anne de Bono who gave comments on an early draft of this article. KK is supported by the National Institute for Health Research (NIHR) Applied Research Collaboration East Midlands (ARC EM) and the NIHR Leicester Biomedical Research Centre (BRC). AM is supported by the NIHR Applied Research Collaboration NW London. This work was developed as part of KK's and AM's role in the NIHR Applied Research Collaboration Programme. The views expressed are those of the authors and not necessarily those of the NIHR, NHS, or the Department of Health and Social Care. KK is member of SAGE and chair of the SAGE Ethncity Subgroup and a member of Independent SAGE.

Competing interests: KK and AM developed with others the Risk Reduction Framework currently being supported by NHS Employers.

1 Singh AK, Gillies CL, Singh R, etal. Prevalence of co-morbidities and their association with mortality in patients with COVID-19: A systematic review and meta-analysis. Diabetes Obes Metab 2020;22:1915-24. doi: 10.1111/dom.14124 pmid: 32573903

2 Khunti K, Routen A, Patel K, etal. Focused action is required to protect ethnic minority populations from COVID-19 post-lockdown. Br J Gen Pract 2021;71:37-40. doi: 10.3399/bjgp21X714581 pmid: 33355159

3 Levene LS, Coles B, Davies MJ, Hanif W, Zaccardi F, Khunti K. COVID-19 cumulative mortality rates for frontline healthcare staff in England. Br J Gen Pract 2020;70:327-8 doi: 10.3399/bjgp20X710837 pmid: 32586803

4 Harvey WA. The disproportionate impact of covid-19 on black health care workers in the U.S Harvard Business Review2020. https://hbr.org/2020/05/the-disproportionate-impact-of-covid19-on-black-health-care-workers-in-the-u-s

5 Centers for Disease Control and Prevention. Characteristics of health care personnel with covid-19-United States, February 12-April 9, 2020. Morb Wkly Rep Mortal 2020. https://stacks.cdc.gov/view/cdc/86727

6 Brookes K, Limbert C, Deacy C, O'Reilly A, Scott S, Thirlaway K. Systematic review: work-related stress and the HSE management standards. Occup Med (Lond) 2013;63:463-72. doi: $10.1093 /$ occmed/kqt078 pmid: 23847137

7 MacKay CJ, Cousins R, Kelly PJ, Lee S, McCaig RH. 'Management Standards' and work-related stress in the UK: Policy background and science. Work Stress 2004:18:91-112doi: 10.1080/02678370410001727474.

8 Majeed A, Molokhia M, Pankhania B, Asanati K. Protecting the health of doctors during the COVID-19 pandemic. BrJ Gen Pract 2020;70:268-9.

doi: 10.3399/bjgp20X709925 pmid: 32393502

9 Jiva M, Chauhan Z, Choudry B, et al. SAAD Score (2) for BAME community during a covid-19 pandemic infection in general practice May 5 2020. https://www.bedshertslmcs.org.uk/wp-content/uploads/2020/05/SAAD-Score-2.pdf

10 Khunti K. Bono Ad, Browne I, et al. Risk reduction framework for NHS staff at risk of covid-19 infection. 2020. https://www.fom.ac.uk/covid-19/update-risk-reduction-framework-for-nhs-staffat-risk-of-covid-19-infection

11 Jankowski J, Davies A, English P, etal. Risk Stratification for healthcare workers during the covid-19 pandemic; using demographics, co-morbid disease and clinical domain in order to assign clinical duties.medRxiv 2020; 2020.05.05.20091967 [Preprint] doi: 10.1101/2020.05.05.20091967
12 Centers for Disease Control and Prevention. Interim operational considerations for public health management of healthcare workers exposed to or with suspected or confirmed covid-19: non-U.S. healthcare settings. 2020. https://www.cdc.gov/coronavirus/2019-ncov/hcp/non-us-settings/public-health-management-hcw-exposed.html.

13 Association of Local Authority Medical advisors. Covid-19 medical risk assessment. Summary-how to assess a worker's vulnerability. 2020. https://alama.org.uk/covid-19-medicalrisk-assessment

14 European Agency for Safety and Health at Work. Covid-19: resources for the workplace. 2020. https://osha.europa.eu/en/themes/covid-19-resources-workplace

15 World Health Organization. Topic 6: understanding and managing clinical risk. 2020. https://www.who.int/patientsafety/education/curriculum/who_mc_topic-6.pdf?ua=1

16 Royal College of Obstetricians \& Gynaecologists. Coronavirus (covid-19), pregnancy and women's health. 2020. https://www.rcog.org.uk/en/guidelines-research-services/coronavirus-covid-19pregnancy-and-womens-health.

17 NHS Employers. Support for staff who are pregnant. 2020. https://www.nhsemployers.org/news/2020/04/updated-guidance-on-supporting-pregnant\%20staff

18 Clift AK, Coupland CAC, Keogh RH, etal. Living risk prediction algorithm (QCOVID) for risk of hospital admission and mortality from coronavirus 19 in adults: national derivation and validation cohort study. BM/2020;371:m3731. doi: 10.1136/bmj.m3731 pmid: 33082154

19 UK Health and Safety Executive. What to include in your covid-19 risk assessment. 2020. https://www.hse.gov.uk/coronavirus/assets/docs/risk-assessment.pdf

20 Registration UK. Evaluation, Authorisation \& restriction of Chemicals. The United Kingdom research study into ethnicity and covid-19 outcomes in healthcare workers. 2020. https://uk-reach.org/main

21 Snapsurvey. SIREN (Sarscov2 Immunity \& REinfection EvaluatioN): the impact of detectable anti SARS-COV-2 antibody on the incidence of covid-19 in healthcare workers. 2020. https://snapsurvey.phe.org.uk/siren

22 Office for National Statistics. Coronavirus (covid-19) related deaths by occupation, England and Wales: deaths registered up to and including 20 April 2020. 2020.

https://www.ons.gov.uk/peoplepopulationandcommunity/healthandsocialcare/causesofdeath/bulletins/coronaviruscovid19relateddeathsbyoccupationenglandandwales/deathsregistereduptoandincluding20april2020

This article is made freely available for use in accordance with BMJ's website terms and conditions for the duration of the covid-19 pandemic or until otherwise determined by BMJ. You may use, download and print the article for any lawful, non-commercial purpose (including text and data mining) provided that all copyright notices and trade marks are retained. 